\title{
Forum
}

\section{Navigational Ideas and the Yorkshire Ripper Investigation}

\author{
Stuart S. Kind \\ (Forensic Science Services Ltd, Harrogate)
}

This paper describes the application of navigational ideas during a late stage of the Yorkshire Ripper investigation. The conclusions reached were irrevocably recorded before the ultimate facts were established by the arrest and conviction of the killer. The reader is invited to assess the degree of success of the method and to rework the data supplied according to his own navigational ideas. The suggestion is made that navigational concepts may become a valuable weapon in the field of crime investigation.

I. INTRODUCTION. Navigational ideas are useful in crime investigation. This is particularly so in those examples ('multiple' or 'series' crimes) where several offences are suspected as having been committed by the same criminal. Such a series is exemplified by the Yorkshire Ripper series of attacks.

The writer's involvement in the Yorkshire Ripper investigation falls into two parts. The first part was as a member of an advisory team, which included four senior police officers. In December 1980, before the arrest of the killer, for a period of seventeen days, this team examined the progress of the investigation.

The second part took place the following year after the arrest of the killer when, with the same four police officers, the writer spent several months reviewing the investigation under the chairmanship of Mr Lawrence Byford, HM Inspector of Constabulary (now Sir Lawrence Byford, HM Chief Inspector of Constabulary).

It would be tempting to illustrate part of this presentation by knowledge which came through membership of the Byford review team (post arrest); hindsight is a powerful ally in argument. However, this paper will be restricted to some aspects of the first period which took place before the arrest of Peter William Sutcliffe.

On Friday, 22 March $198 \mathrm{I}$, Sutcliffe was convicted of thirteen murders and seven attempted murders in the Yorkshire Ripper series. He was sentenced to 20 concurrent terms of life imprisonment with a recommendation that he should serve a minimum of 30 years.

2. THE INVESTIGATIVE PROCESs. A scientist produces hypotheses by inductive inference. That is to say he combines a number of individual findings into a general statement which, he believes, accounts for the individual facts. The mental procedure of producing hypotheses is extremely complex and does not concern us here. Our approach will be strictly pragmatical.

The scientist next deduces some logical consequences of his views. These he then subjects to experimental test. Likewise the police investigator may produce a hypothesis (called in his case a 'hunch') which he subjects to test by adopting particular lines of enquiry. The logical pattern is the same in both examples. 
If the hypothesis or hunch survives the test then one may consider it confirmed, or at least supported, keeping in mind that logically speaking one can never totally establish a hypothesis (the next experiment may prove you wrong). However, the essence of the matter is that one commits oneself to a particular view in advance of the facts being established.

Einstein predicted the gravitational bending of light rays as a deduced result of the Theory of Relativity. The predicted bending was observed experimentally and this was taken as support for the theory. An air navigator (of which the writer was a wartime example) may predict his track and estimated time of arrival. He may arrive where and when he predicts. Error in the first example may lead to a rethinking of scientific concepts. Error in the second, like errors by crime investigators, may lead to fatal consequences.

3. THE YORKSHIRE RIPPER SERIES. At the end of November i 980 , except for a single meeting with some colleagues who were professionally involved in the investigation, the writer's entire knowledge of the Yorkshire Ripper investigation stemmed from newspaper reports since, although a professional forensic scientist, he had held a research job for the previous four years.

There was widespread public disquiet at the time. The female population of the North of England was terrorized to a degree which it is hard to conceive so long after the events. Personal disquiet at the situation was expressed by the Prime Minister and the Home Secretary, and it was as a result of this that a visit was made by $\mathrm{Mr}$ Lawrence Byford to the Chief Constable of the West Yorkshire Metropolitan Police (Mr Ronald Gregory) during November 1980.

The immediate consequence of this visit was that an advisory group was set up to review the Yorkshire Ripper investigation, as it had unfolded during the previous five and a half years, with a view to making recommendations for any change of direction which might be thought necessary in the pattern of enquiries.

The Advisory Group consisted of Mr Leslie Emment (Deputy Chief Constable, Thames Valley Police), Mr David Gerty, (Assistant Chief Constable, West Midlands Police), Mr Ronald Harvey, (Assistant to Her Majesty's Chief Inspector of Constabulary), Mr Andrew Sloan (Assistant Chief Constable, Lincolnshire Police) and the writer (Director, Home Office Central Research Establishment).

The work of the advisory group started on 1 December 1980 and continued until 17 December 1980 when, with the production of an interim advisory report for the Chief Constable of the West Yorkshire Metropolitan Police, the work temporarily ceased. An intention to return to the task the following month proved superfluous because Sutcliffe was arrested in Sheffield on 2 January $198 \mathrm{I}$. It is necessary to point out here that the circumstances of Sutcliffe's arrest owed nothing to the work of the advisory group but were simply a consequence of good routine police work by South Yorkshire Police aided by efficient radio communications and by the excellent Home Office Police National Computer Unit.

The situation found by the five-member team as work began at the beginning of December 1980, was that there were seventeen established Ripper victims of which thirteen were murders and four were assaults (see Table I). 'Established' simply means those cases which, at that time, for the purpose of the investigation, were accepted as belonging to the series. Of those seventeen cases, fifteen of them were accepted with some confidence as belonging to the series but two of them, No. 4 (Harrison, Preston, 20 November 1975) and No. I 2 (Pearson, Bradford, 21 January 1978) were considered as doubtful members of the series.

Over the seventeen days of the exercise the group read many case files and reports, 
Table I. The Seventeen assumed Yorkshire Ripper attacks Which Were considered by the ADVISORY TEAM

\begin{tabular}{|c|c|c|c|c|c|c|c|}
\hline \multirow{2}{*}{$\begin{array}{l}\text { Offence } \\
\text { no. }\end{array}$} & \multirow[b]{2}{*}{ Day } & \multirow[b]{2}{*}{ Date } & \multirow[b]{2}{*}{ Location } & \multicolumn{2}{|c|}{$\begin{array}{c}\text { Time victim } \\
\text { last seen/assaulted }\end{array}$} & \multirow[b]{2}{*}{ Offence } & \multirow[b]{2}{*}{ Victim } \\
\hline & & & & Clock & GMT & & \\
\hline 1 & Saturday & 5 July 1975 & Keighley & 0110 & Doro & Assault & Anne Rogulskyj \\
\hline 2 & Friday & is Aug. 1975 & Halifax & 2300 & 2200 & Assault & Olive Smelt \\
\hline 3 & Thursday & 30 Oct. 1975 & Leeds & 0115 & 0115 & Murder & Wilma McCann \\
\hline 4 & Thursday & 20 Nov. 1975 & Preston & 2220 & 2220 & Murder & Joan Marrison \\
\hline 5 & Tuesday & 20 Jan. 1976 & Leeds & 1900 & 1900 & Murder & Emily Jackson \\
\hline 6 & Saturday & 5 Feb. 1977 & Leeds & 2330 & 2330 & Murder & Irene Richardson \\
\hline 7 & Saturday & 23 Apr. 1977 & Bradford & 2315 & 2215 & Murder & Patricia Atkinson \\
\hline 8 & Sunday & 26 Jine 1977 & Leeds & 0145 & 0045 & Murder & Jayne MacDonald \\
\hline 9 & Sunday & to July 1977 & Bradford & 0100 & 2400 & Assault & Maureen Long \\
\hline 10 & Saturday & I Oct. 1977 & Manchester & 2130 & 2030 & Murder & Jean Jordan \\
\hline 1 & Wednesday & ${ }_{14}$ Dec. 1977 & Leeds & 2000 & 2000 & Assault & Marilyn Moore \\
\hline 12 & Saturday & 21 Jan. 1978 & Bradford & 2130 & $2 \times 30$ & Murder & Yvonne Pearson \\
\hline 3 & Tuesday & 31 Jan. 1978 & Huddersfield & 2110 & 2110 & Murder & Elena Rytka \\
\hline 14 & Tuesday & 16 May 1978 & Manchester & 2200 & 2100 & Murder & Vera Millward \\
\hline 15 & Wednesday & ${ }_{4}$ Apr. 1979 & Halifax & 2330 & 2230 & Murder & Josephine Whitaker \\
\hline 16 & Sunday & 2 Sep. 1979 & Bradford & 0215 & 0115 & Murder & Barbara Leach \\
\hline 7 & Monday & 17 Nov. 1980 & Leeds & 2120 & 2120 & Murder & Jacqueline Hill \\
\hline
\end{tabular}

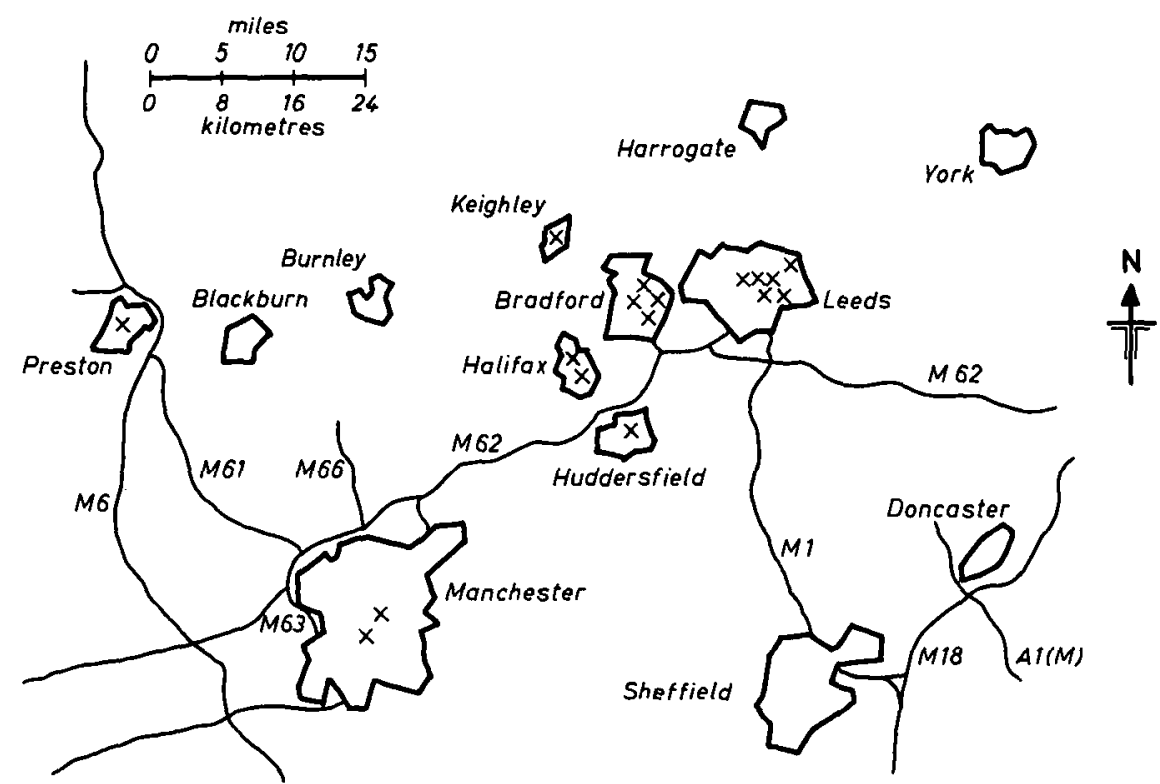

Fig. 1. Distribution of the seventeen assumed Ripper offences as at December 1980

interviewed many police officers (singly and in groups), visited scenes of Ripper crimes and conferred together at length.

The Ripper offences, as far as then known, were restricted to the North of England and consideration was given to cases throughout West Yorkshire and in Greater Manchester and in Preston. At the time the group started work the Yorkshire Ripper investigation involved several hundreds of police officers and it had been under way in one form or another since 1975. Table I gives date, location and time of each of the seventeen attacks. Figure 1 gives the geographical location of the attacks.

At the end of 1980 the pattern of the investigation was substantially polarized by the 
view of the chief investigating officer that certain letters and a tape recording which he had received originated from the Yorkshire Ripper. From this view arose the idea that the Ripper had a Geordie (Sunderland) accent and much of the investigation was based upon this assumption. The argument for adopting this view was that certain information in the letters and the tape could only have been known to the Ripper himself.

After considering the content of the letters and the tape, together with various reports which had appeared in the media throughout the several years of the Yorkshire Ripper investigation, the group concluded that it was by no means established that the tape and letters came from the killer. All the information which was supposedly private to the Ripper had been available, somewhere or other in the press, although it is true to say that it would have taken a degree of dedication for a person unassociated with the investigation to search for and to assemble it. There was, furthermore, some evidence which positively indicated that the letters and the tape were a hoax. It is only fair to add that this was a view which was fairly widespread amongst many of the investigating police officers themselves.

Having disposed of the necessity to assume that the Ripper was a Geordie the view gradually developed amongst the members of the advisory group that the Ripper was a local man. 'Local' in this sense meant the Bradford and Leeds areas with preference for Bradford. The reasons this view was adopted were many and complex and no attempt will be made to analyse and present them here except to say that it developed gradually and as a consequence of a barrage of information imposed upon fresh professional minds. But whatever the reasons for the hypothesis it was one which was intuitively held by the group. So, having formulated the hypothesis that the Ripper was a local man, was there any way it could be tested?

There were seventeen cases to work on where the locations of the attacks were known to a high degree of confidence. The times of the attacks were less precisely known since in some instances the body was not discovered until some time after the attack. However one factor was exactly known in each case where the time of attack was doubtful. This was the 'time-last-seen-alive'. There were good reasons in most cases for assuming this to be shortly before the attack.

4. THE TwO NAVIGational tests. For the purposes of this paper we must disregard the exact nature of the the welter of information, much of it conflicting, which led the group to formulate the idea that the Ripper was a local man. It is, however, useful to note two pieces of valuable physical evidence which were available at the time.

The first of these was that in three of the cases, No. 6 (Richardson, Leeds, 5 February 1977), No. I I (Moore, Leeds, 14 December 1977) and No. 14 (Millward, Manchester, 16 May 1978) motor-car tyre tracks had been left at the scenes of crime. The tyre tracks were sufficiently informative to suggest that the same vehicle had been used on each occasion.

The other piece of physical evidence was that a new five-pound note had been found in the handbag of victim No. 10 (Jordan, Manchester, I October 1977). This had been issued between Thursday 29 September and Saturday 1 October 1977 by one of two banks both of which were located in North Bradford (Manningham and Shipley). This was the only money in the deceased's handbag. It was assumed to be payment for prostitution since five pounds in advance was the going rate for that class of prostitute in that area at the time. The fact that the note had been issued in Yorkshire, where eight of the previous nine Ripper cases had occurred, was taken to be highly significant.

5. THE FIRST NAVIGATIONAL TEST. The first test to be applied to the hypothesis that the Ripper was a local man was to compute the 'centre of gravity' of the offences 
without regard to when they occurred. 'Centre of gravity' in this context can best be visualized by the following example.

Take a map of the area in which the seventeen Yorkshire Ripper offences occurred and mark the location of each by a pin. Next take an eighteenth pin and join it to each of the seventeen locations by a piece of thread. That location of the eighteenth pin which minimizes the amount of thread required is the centre of gravity of the seventeen offences.

In fact the exercise was carried out on computer at the Home Office Central Research Establishment. The calculations were performed on the basis of the simplest possible pattern, that is distances as the crow flies. Six different exercises were carried out. These were based on six different sets of assumptions as to which of the seventeen cases were in fact Ripper cases. The centre of gravity proved to be in all cases near the City of Bradford (see Fig. 2).

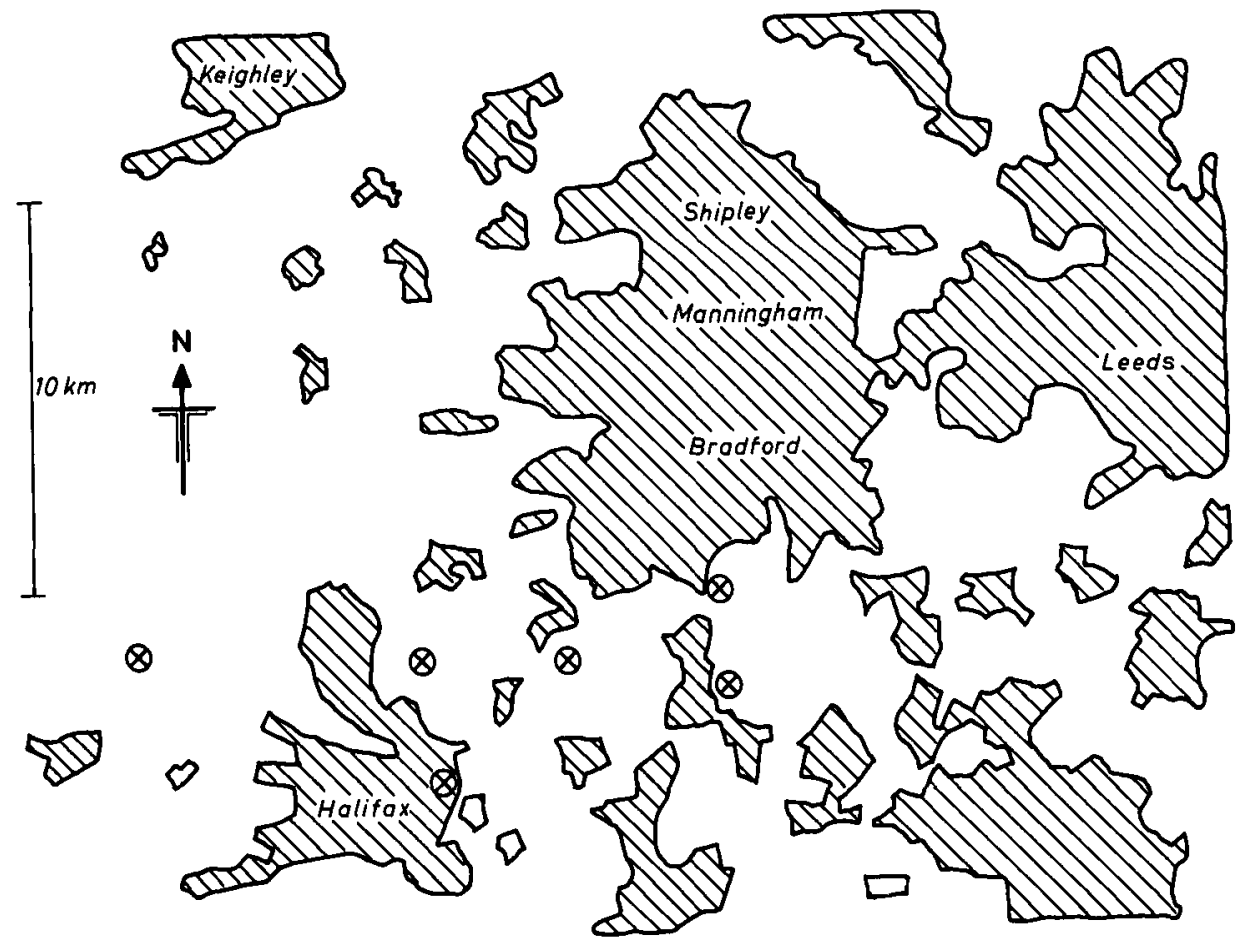

Fig. 2. The centres of gravity for six different sets of assumptions made at the time as to which of the seventeen offences were, or were not, Ripper offences. This is an exact reproduction of the locations noted in December 1980

The justification for the test was simply that criminals, like non-criminals, are subject to the constraints of time and space in all their activities. The possibility that a criminal may act in such a way as deliberately to cover his tracks must be balanced against the natural human tendency to gain results with minimum effort. Neither should one forget the fourteenth-century dictum of William of Ockham (Occam's Razor), 'entities should not be multiplied without necessity' or, put another way, keep hypotheses as simple as the data permit.

6. THE SECOND NAVIGATIONAL TEST. The second test made on the seventeen 
sets of data points concerned the possible effect on the timing of the crimes if the Ripper operated from a single location. The reasoning behind this test went thus: If the killer seeks his victims wherever he can find them and then returns to his base as quickly as possible, he will have the tendency to attack later in the day the closer he is to base. The reason for this tendency is to minimize the risk of being held up on the way home should the crime be swiftly discovered.

In the seventeen established cases the Ripper had attacked exclusively after sunset. Because of this, in the summer-time the attacks tended to be later. The question to be asked was therefore 'if this trend were compensated for, would any correlation of time and location be discernible?'

The method adopted was simply to plot a graph with clock time on the ordinate and day length on the abscissa. This method was adopted because the assessment was carried out in haste, in the early hours of the morning, in an hotel bedroom. No diary with sunset times was available so day length was computed roughly by taking December as the month of the shortest days, June as the month of the longest days and the other ten months were paired in five groups of two. The intention was to refine the hastily performed calculation when sunset times became available but, in the event, this was not done before the arrest of the Ripper.

Certain questions will doubtless occur to the navigator on reading the above paragraph but they will not be dealt with here simply because they did not occur to the writer at the time. Those who have experienced the necessity to perform quick approximate calculations, when fatigued, will doubtless understand why.

The graph so produced (of which Fig. 3 is a legible and quantitatively precise reproduction) showed a distinct seasonal trend in attack times. Allowing for this seasonal trend it appeared to the writer, at the time, that the later attacks were those located near Leeds and Bradford just as the hypothesis demanded.

7. THE BROAD BASIS DOCUMENT. Having absorbed a large amount of information, and having seen the hypothesis pass two metrical tests, the conviction grew upon the writer that the Ripper was indeed a local man. This view was transmitted to the Operational Services Division of the Home Office Central Research Establishment and was reproduced as a Broad Basis document which was circulated on 10 December 1980 . Among a number of clauses, the relevant ones were:

(2) The centre of gravity of the incidents, weighted and unweighted, tends to be near Bradford.

(3) Time of offence correlates well with day length but the late 'fliers' tend to be in Leeds and Bradford.

The document also contained the suggestion that the Ripper lived in or near Bradford, possibly in the Manningham or Shipley area.

The human mind tends to rationalize conclusions arrived at on a purely intuitive basis and so the reader must decide for himself how convincing he finds the Broad Basis document clauses as a reflection of the reasoning processes involved. But whatever view is taken of the matter one must accept the fact that the document was drafted, filed and distributed before the matter was finally determined by the arrest of the Ripper.

Readers may find it instructive to work on the data in Table $I$ in their own ways and to see what conclusions they arrive at. These may, of course may be additional to (or even different from!) those of the writer.

8. INTERIM REPORT AND THE ARREST. On if December 1980 the group produced an interim report for the Chief Constable of the West Yorkshire Metropolitan Police. Inter alia the report recommended that a special team of high-grade detectives be dedicated to enquiries in the Bradford area. It was the intention of the group to return 


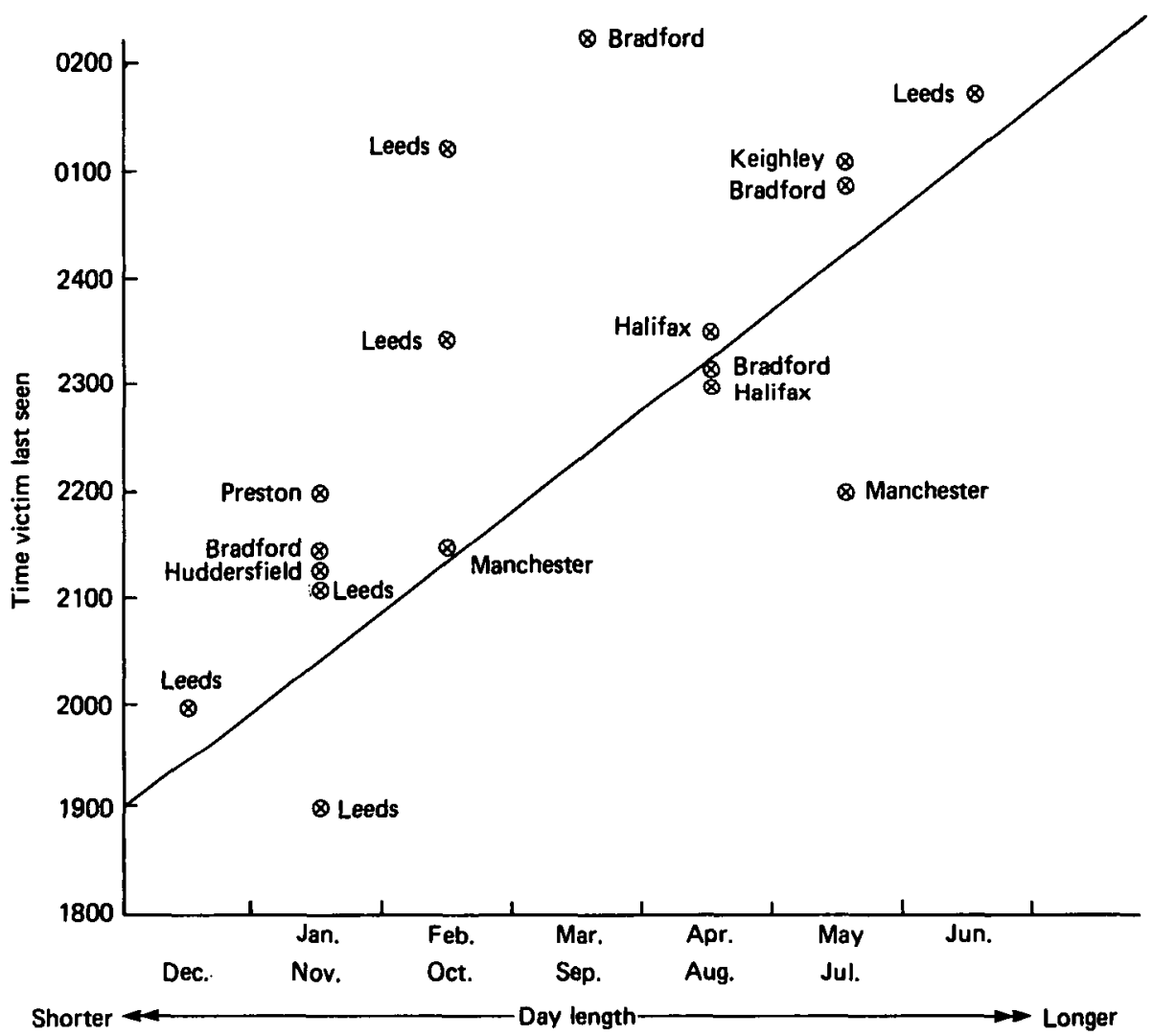

Fig. 3. The data from Table I plotted as clock time (ordinates) and day length (abscissa). The data for attack No. 9 (see Table I) was plotted too early in error. Correct plotting lends added strength to the hypothesis. It is instructive to rework the data in the form of a simple rank order after sunset, particularly in the light of the special status of attack No. 4. This was the only one of the seventeen attacks to which Peter William Sutcliffe did not plead guilty

to its task early in the New Year and to monitor how effectively the recommendations has been put into effect. This return proved unnecessary.

At 10.50 p.m. on Friday 2 January 1981 , Sergeant Robert Ring and Constable Robert John Hydes of the South Yorkshire Police were on motor-patrol duty in the City of Sheffield. There they questioned, and later arrested, Peter William Sutcliffe. Sutcliffe was later charged with and convicted of, inter alia, all the crimes listed in Table I with the exception of No. 4. Sutcliffe was a native of Bradford who spoke with a Bradford accent. He lived in the district of Heaton in Bradford. Heaton is located midway between Manningham and Shipley.

9. DISCUSSION. Such results as were obtained in the exercise described above were a consequence of the work of the group as a whole. The expertise of the forensic scientist cannot be applied in a vacuum. Experience clearly shows that the closer the cooperation between the investigator and his scientific advisers the more efficiently may specialist techniques be applied. Indeed it may even be said that given sufficient and sufficiently expert briefing, the way to proceed for the scientific adviser becomes so obvious as to be trite. Certainly one could hardly claim any measure of originality for the tests used here as scientific methods per se. 
Yet the investigation had been under way in one form or another for five and a half years. As the investigation developed, more data points (if one is ever justified in describing human tragedy in such a way) became available. At what stage of the investigation might the same methods have been applied to demonstrate the same ideas discussed here? Perhaps some navigator with an interest in crime investigation might care to rework the data available after each crime! Certainly it appears no one applied the approach described here yet hundreds of competent police investigators, and dozens of expert forensic scientists had been involved in the investigation and millions of pounds of taxpayers' money had been spent.

Criticism is sometimes made that the applications of the lessons to be learned from the failures in the Yorkshire Ripper investigation have been placed entirely in the hands of those who failed in the first place. But it is difficult to see how things could, for the most part, be otherwise. Were every failure in human affairs to be the signal for a purge of those who failed then it is doubtful if lessons could ever be learned.

It is only fair to say that the agencies involved in the matter (for the most part the Home Office and the police service itself) have made great efforts to identify and teach the lessons to be learned to those involved in crime investigation. Much of this work has been attended by success. Few would dispute that the computer facilities now available are much superior to those which were available throughout the Yorkshire Ripper investigation. The Holmes (Home Office Large Major Enquiry System) computer facility for the police is a case in point. Much of this success stems from the work of the Major Crime Working Group of the Association of Chief Police Officers, a group which was set up by ACPO as a consequence of the Byford Review.

Yet there currently seems to be an overwhelming view that the lessons to be learned can be distilled in their entirety in the form of 'procedures'and 'guidelines'. This attitude seems to be a consequence of it being produced by agencies whose main business it is to produce policy as distinct from operational solutions.

Doubtless policy is extremely useful but only if it does not automatically exclude the application of incisive and entreprenurial investigation techniques. The navigator who loses his aircraft despite having strictly followed the rules, but showed no imagination, is hardly free from blame. Habits of bureaucratic thought must not resist the free introduction of new ideas into crime investigation and it is here that the navigator (be he professionally a sailor, a flier, a scientist or a policeman) can help.

Was the application of navigational concepts into the Yorkshire Ripper Investigation a legitimate extension of their use? Might such ideas be applicable in other multiple-crime investigations either in the same or in a modified form? Are such concepts only of use where several crimes, suspected of being committed by the same person, are involved?

On the other hand are parameters such as locations and times relating to victims and suspects in the single crime, amenable to 'navigational' treatment? Take for example the following case which, although hypothetical, has sufficient similarity to real problems to render any solution practically useful.

A woman leaves her house by car at a known time and is not seen again. Her car is found in a lay-by in a sparsely populated moorland area of the country. The man with whom she is associating is seen at a certain location and time and subsequently at another location and time. If he is responsible for the disappearance of the woman in the intervening period then can navigational ideas be used to optimize the search for the body?

Such a problem as this, given to a scientist, may well lead to elegant solutions. For all the writer knows it may be a type of problem already worked on by scientists but, to be practically useful, not only must the solution be 'correct' but it must also be framed 
in a way useable by those whose job it is to solve practical problems. In the real situation it is better to be master of a little science rather than the slave of much. The approximate methods of the navigator are far more likely to be useful in crime investigation than the elegant solutions of the mathematician.

ACKNOWLEDGEMENTS. The credit for any potential usefulness, or for any apparent originality, of the views expressed here, is largely due to the professional competence, friendship and stimulating company of the police colleagues named earlier in this article. The inadequacies are entirely the writer's.

\title{
Position Fixing with Neither Dead Reckoning nor GMT
}

\author{
W. B. Fu \\ (Hong Kong Polytechnic)
}

This is a short summary of a paper which shows what a navigator can do to fix his position at sea using basic equipment (sextant, hand-held compass, almanac, four-figure mathematical tables) without the help of dead reckoning or the benefits of GMT.

To proceed from an almost complete absence of spatial and temporal data the navigator has to observe the sextant altitudes $\left(A_{1}, A_{2}, A_{3}\right)$ of two stars and the Moon, respectively. Using the measurements $\left(A_{1}, A_{2}\right)$ of the stars and data provided by the almanac on their declinations $\left(D_{1}, D_{2}\right)$ and sidereal hour angles $\left(S_{1}, S_{2}\right)$ the navigator can calculate his latitude $(L)$ by the iterative solution of an equation derivable from spherical trigonometry:

where

$$
\arccos \left(H_{1}\right)+\arccos \left(H_{2}\right)-S_{1}+S_{2}=0
$$

$$
H_{1}=\frac{\sin A_{1}-\sin L \sin D_{i}}{\cos L \cos D_{1}} \quad(i=1,2)
$$

From this value of the latitude he can deduce the local hour angle of Aries. He then combines these calculated results with the lunar altitude $\left(A_{3}\right)$ to determine the GMT by solving iteratively another equation from spherical trigonometry:

$$
\sin A_{3}-\sin L \sin D_{3}-\cos L \cos D_{3} \cos H_{3}=0
$$

Here $D_{3}$ and $H_{3}$, which are time-dependent quantities, denote respectively the declination and local hour angle of the Moon.

The GMT having been found, the navigator can easily deduce his longitude. With care the results for both the latitude and longitude can be obtained to the nearest minute of arc. The penalty for the almost complete ignorance of one's position and time is a great deal of numerical work which may be too demanding for navigators with only an O-level in mathematics.

The present method is different in principle from the now obsolete lunar distance method which requires the measurements of the altitude of the Moon and one star, and the angular distance between them.

Readers who are interested in this subject are invited to write to the author, care of the RIN for details. 